\title{
Variability of the water stock dynamics in karst: insights from surface-to-tunnel geophysics
}

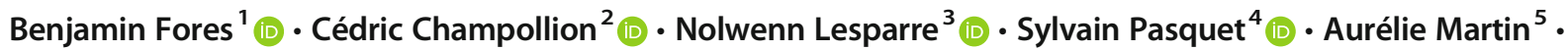 \\ Frédéric Nguyen ${ }^{6}$
}

Received: 24 July 2020 / Accepted: 12 May 2021

(C) Springer-Verlag GmbH Germany, part of Springer Nature 2021

\begin{abstract}
A hydrogeophysical field experiment was conducted on a karst hydrosystem in the south of France to investigate groundwater transfer and storage variability at a scale of a few hundred meters. A 200-m-long N/S tunnel going through limestone provided the unique opportunity to set up measurements with original configurations inside the unsaturated zone. Three geophysical methods were used: gravimetry, electrical, and seismic. Two-dimensional electrical resistivity and seismic velocity images were retrieved by surrounding the medium with electrodes and geophones, both at the surface and inside the tunnel to improve the sensitivity in depth. This gave information about the weathering state but also about the limestone content and associated porosity characteristics, as the methods are sensitive to distinct properties with different resolution patterns. A time-lapse gravity surfaceto-tunnel profile supplied information on the seasonal water mass changes and its variations along the tunnel. Besides, tracers were injected on each side of the profile from the surface and the restitution was sampled in the tunnel drip flows. A contrasting hydrological behavior was evidenced on each side of the tunnel from temporal gravity measurements and tracing tests. The analysis of the whole dataset allowed for better interpretation of the imaged structures, with different hydrological functioning. This study demonstrates the variability of the karst behavior at the scale of a few hundred meters and the benefits of a multimethod approach coupling hydrological and geophysical measurements. This kind of experiment provides fundamental understanding of systems that cannot be directly observed.
\end{abstract}

Keywords Karst $\cdot$ Heterogeneity $\cdot$ Geophysical methods $\cdot$ Unsaturated zone

Benjamin Fores

benjamin.fores@uni.lu

1 Research Unit in Engineering Science, University of Luxembourg, Esch-sur-Alzette, Luxembourg

2 Laboratoire Géosciences Montpellier, CNRS UMR 5243, Université Montpellier, Montpellier, France

3 Université de Strasbourg, CNRS, UMR 7517, F-67000 Strasbourg, France

4 Université de Paris, Institut de physique du globe de Paris, CNRS, F-75005 Paris, France

5 Geology and Applied Geology, Faculty of Engineering, University of Mons, Mons, Belgium

6 Urban and Environmental Engineering, Applied Geophysics, Liege University, Liege, Belgium

\section{Introduction}

A quarter of the world relies on carbonate aquifers for its freshwater needs (Ford and Williams, 2013). Those aquifers, subject to complex karstification processes, are highly heterogeneous from the pore-scale to the basin scale. They are often seen as compartmentalized, with a buffering epikarst close to the surface (Klimchouk 2004). The latter can be considered as a more weathered, more porous and more homogeneous zone compared to an underlying massive medium crossed by fractures and/or karstic channels. Given its higher porosity, the epikarst is more permeable and is considered as an active zone favoring infiltration. Karstic aquifers are also laterally heterogeneous with sinkholes acting as infiltration points, spatially variable weathering, localized fractures and extremely transmissive network of drains. Each of these features are inherited from the karst evolution history, which depends on the landscape, climate, vegetation, geological settings, carbonates nature, preexisting fractures (e.g. ghost rocks karstification: Dubois 
et al. 2014; epikarst weathering: Klimchouk 2004). Such heterogeneity is challenging to assess and to account for in models for both scientific or groundwater resources management studies (Dentz et al. 2011), making the comparison and combination of data at different scales very difficult (Dausse et al. 2015). In karstic environments, boreholes provide very localized information which usually cannot be interpolated at the scale of the catchment, nor a few meters away (e.g. Noushabadi et al. 2011). At the opposite scale, springs studies (geochemical, hydrogram analyses; e.g. Bicalho et al. 2019; Mazzilli et al. 2019) integrate information about structures and processes taking place across the entire catchment. Between those two end members, the water storage capacity is likely to strongly fluctuate in space over the watershed (Vouillamoz et al. 2003; Jacob et al. 2010; Mazzilli et al. 2016).

Spatialized models at the catchment scale (Hartmann et al. 2014) require distributed data to inform the medium permeability and the dynamics of water circulation. In this context, geophysical imaging methods are pertinent tools to identify hydrofacies distribution (Al-Fares et al. 2002; Valois et al. 2011; Chalikakis et al. 2011; Carrière et al. 2013; Pasquet et al. 2016; Novitsky et al. 2018). Geophysical properties often reflect many properties of the medium such as lithology, the degree of weathering/fracturing, salinity or water content. To grasp a better understanding of complex systems such as karsts, multiple geophysical methods are often colocalized and jointly interpreted (e.g. Gallardo and Meju 2003; Robert et al. 2011; Valois et al. 2011). Whereas different geophysical methods are often complementary, one still requires additional information to constraint joint interpretation. This information can take the form of prior knowledge in a joint inversion process (e.g. Gallardo and Meju 2003), invasive sampling or more recently time-lapse surveys (e.g. Robert et al. 2012; Valois et al. 2016; Watlet et al. 2018). Joint inversion typically requires one to constrain the inverted parameters together using structural prior or petrophysical relationships. Such constraints are in practice difficult to achieve successfully in complex systems such as karst given the variability of the physical properties. In some sites, human-made or natural structures allow one to make multidirectional measurements, with sensors surrounding the medium to better characterize it. They often require specific methodological approaches to account for the uncommon survey geometries, e.g. surface-to-borehole (Tsourlos et al. 2011), surface-to-tunnel (Gritto et al. 2004; Simyrdanis et al. 2015; Lesparre et al. 2016), surface-to-cliff (Dussauge-Peisser et al. 2003; Jeannin et al. 2006). In cases where existing tunnels are available, they provide a singular surface-to-depth geometry for gravity measurements leading to a direct and unique insight on the water mass variations in the medium in between the surface and depth acquisition points (Jacob et al. 2009; Champollion et al. 2018). Such configurations allow a considerable improvement of the spatial resolution of the geophysical images in depth (Maufroy et al. 2014; Lesparre et al. 2016), leading to more reliable interpretation of geophysical images. In karstic systems, time-lapse micro-gravity experiments complete characterization studies by shedding light on the heterogeneity of an aquifer in terms of water storage dynamics (Jacob et al. 2010; Hinderer et al. 2016). The latter is informed without ambiguity through time-lapse gravity within a radius of tens to hundreds of meters around the instrument (e.g. Gehman et al. 2009; Creutzfeldt et al. 2010; Pfeffer et al. 2013; Piccolroaz et al. 2015).

In this study, an innovative hydrogeophysical experiment is performed to explore the water storage dynamics heterogeneity at the intermediate scale of a few hundreds of meters in a shallow karst on the Larzac plateau (south of France). This unique experimental dataset provides a rare opportunity to better understand how epikarst heterogeneity and fractures affect water storage dynamics. A tracing experiment is combined with time-lapse gravimetry, electrical resistivity tomography (ERT) and seismic refraction tomography (SRT) to understand how the structural information validates the hypothesis inferred from the observed temporal water changes and vice-versa. The presence of a $200-\mathrm{m}$-long tunnel allows implementing surface-to-tunnel (S2T) measurements. Observations given by the different data types are analyzed together in light of the geological and hydrological field observations across the watershed and along the tunnel walls.

In the following, the geological and hydro-meteorological context of the experiment are presented. Then, the methodology of tracing tests and geophysical experiments are described: time-lapse S2T gravimetry for storage changes and static S2T SRT and ERT images of the underground structures. Finally, the results are described with a discussion about how the observed water storage dynamic spatial variations might be explained by the presence of structures with different hydrogeological properties. A conceptual model details the role of the identified compartments on the different water transfer processes involved. Finally, the benefits and resolution improvements of such S2T configurations are discussed.

\section{Site description}

The experiment takes place along and above the tunnel of Saint-Ferréol, located on the south part of the Campestre karstic plateau (a part of the Larzac karstic plateau) in the south of France. The Campestre plateau's elevation varies between 600 and $900 \mathrm{~m}$ asl and has a small area of $36 \mathrm{~km}^{2}$ covered by fields and pine forests.

\section{Hydrogeological context}

The Campestre plateau is mainly made of limestones, dolostones and marls deposited during marine regressions around -150 Myr. The climate is Mediterranean with dry summers, wet winters and springs, while extreme rainfall 
events happen regularly in the fall. Annual precipitation strongly varies between 1,050 and 1,650 $\mathrm{mm}$ a year (MétéoFrance, ALZON station, years 2011 to 2015). The plateau is highly karstified, which explains the absence of perennial surface stream. An active network of karst conduits (e.g. Mangin 1975) is expected to conduct the water falling on the Campestre plateau towards the "Foux de la Vis" karstic spring, $8 \mathrm{~km}$ south-east (Bruxelles 2001). The soil is thin and disappears towards the south where limestone outcrops are common. The volume investigated with geophysical methods (from the tunnel to the surface) is made entirely of Thitonian limestone whose thickness may be greater than $150 \mathrm{~m}$ (Bruxelles 2001). Stratification in the tunnel shows a small and constant $10^{\circ}$ dip to the east. Fractures observed on the tunnel walls are mainly $\sim \mathrm{N} 140-180$ with $50-90^{\circ}$ dip to the west, which is consistent with the geological map (Gèze 1985).

\section{Tunnel configuration}

The tunnel is $220 \mathrm{~m}$ long and is oriented $\mathrm{N}-\mathrm{S}$, with a section of about $2 \mathrm{~m} \times 2 \mathrm{~m}$ (Fig. 1). It is entirely manmade and was dug for commercial purposes at the end of the nineteenth century to connect the bottom of a sinkhole (called a "doline" in this region), easily reachable, and a large cavity at the bottom of a $60 \mathrm{~m}$ depth abyss (Fig. 1), to store and mature Roquefort cheese. The entrance of the tunnel is located $30 \mathrm{~m}$ beneath the plateau (which is $700 \mathrm{~m}$ asl) on the sinkhole side (south). The tunnel presents a descending slope varying between 10 and $15 \%$ towards the abyss (north) and leading to the cavity $60 \mathrm{~m}$ beneath the plateau. Surface topography shows a slight dip to the SW, with pines to the east and fields to the west.

The tunnel section (see Fig. 2) near the sinkhole has a very regular shape dug in massive limestone. Approaching the abyss, the limestone becomes more and more fractured with marks of runoff on the walls and on the roof. A pile of rubble is followed by a reinforced masonry vault between 160 and $190 \mathrm{~m}$ (Fig. 2), highlighting an unstable section. Observations of drops falling in the tunnel provide insights on the water transfers occurring above the tunnel. The following qualitative observations were made during gravity measurements and water sampling for tracer tests. Over the entire distance of the tunnel, the relationship between heavy rainfalls and drip flows is pronounced; however, in the first $50 \mathrm{~m}$ from the tunnel entrance located on the sinkhole side, drip flows dry up after a few weeks without important rainfall events. On the other hand, in the last $50 \mathrm{~m}$ of the tunnel (abyss side), a different behavior is observed with perennial drip flows subsisting after several months without precipitation at the surface, even though flows are then weaker (Fig. 2). One can also note the existence of a small spring on the wall near the abyss at about $200 \mathrm{~m}$ from the tunnel entrance. This spring has a sustained output and shows important concretions. Finally, a few clay pockets (mainly kaolinite) are observed on the tunnel roof and walls, on the second half of the tunnel only and especially close to the abyss (Bruxelles 2001).
Fig. 1 Aerial image of the site located on the Campestre plateau showing the tunnel, abyss and sinkhole positions. The colorscale represents the elevation of the tunnel and abyss. Topographic isolines have a height interval of $5 \mathrm{~m}$

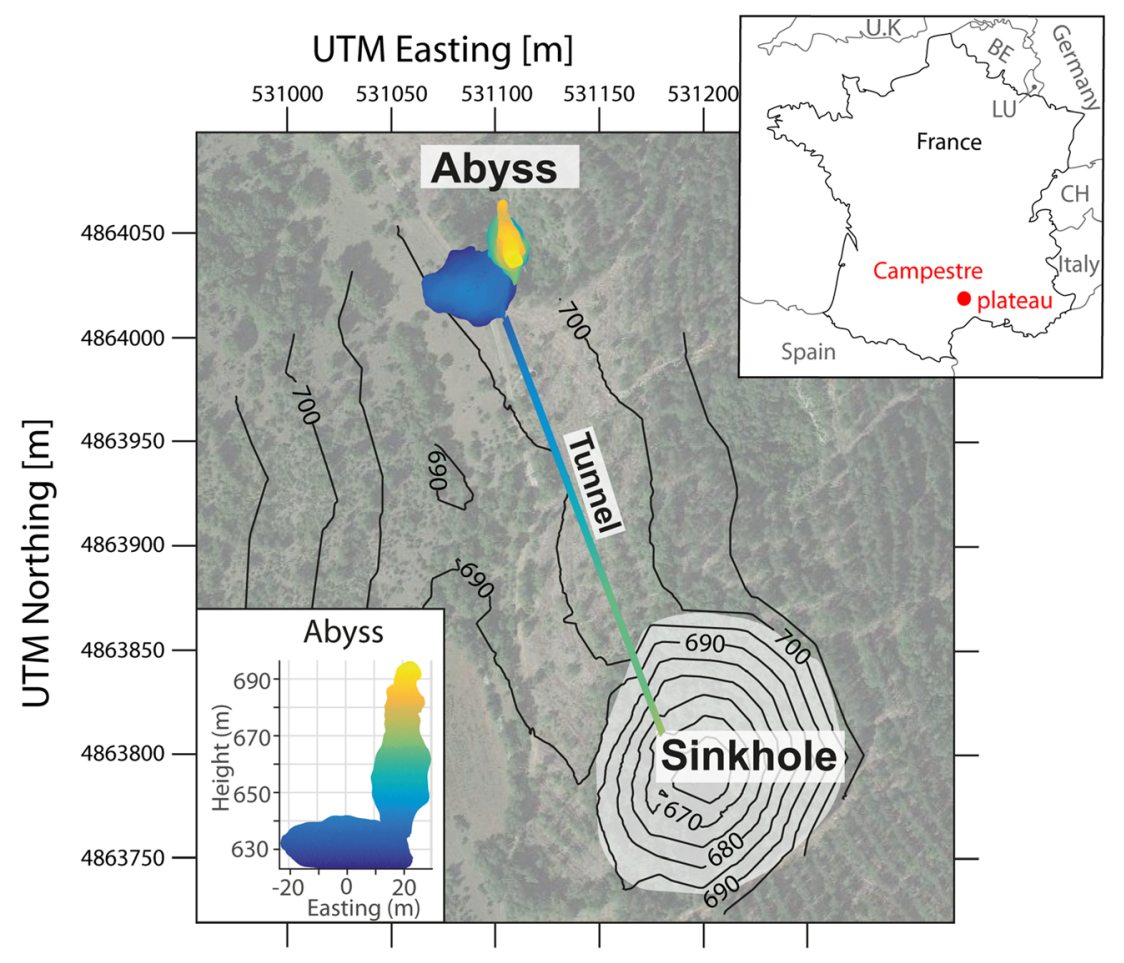


Fig. 2 S-N vertical cross-section of the tunnel connecting the sinkhole and the abyss, showing the configuration of all the geophysical experiments (gravimetric stations, electrodes, geophones) and hydrological experiments (tracings and drip flows observations)

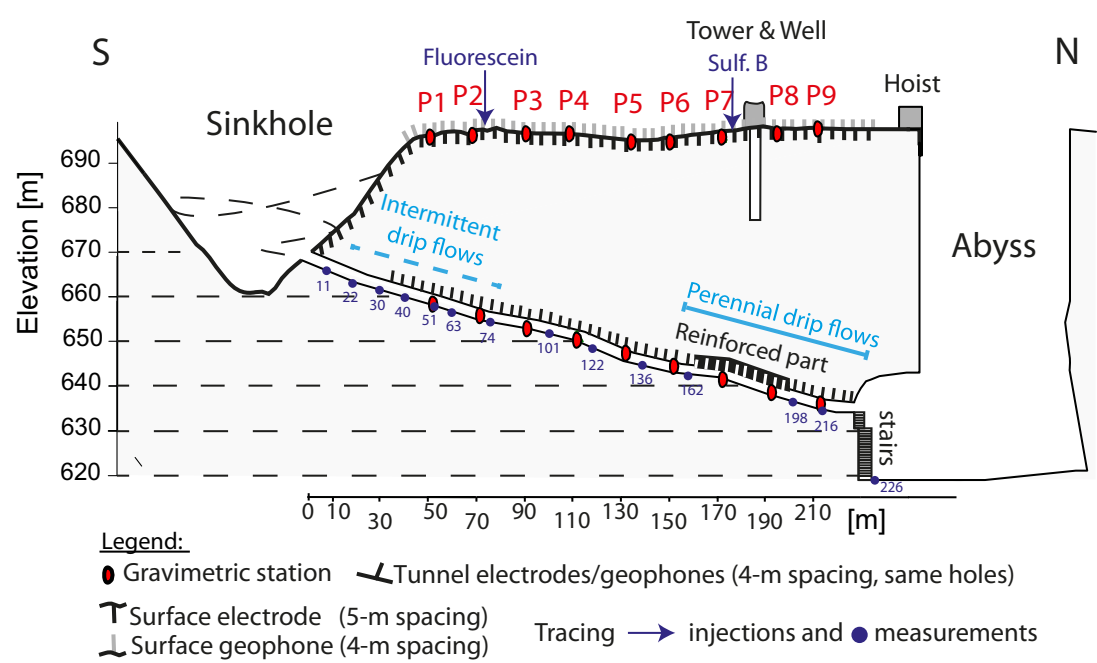

\section{Methods}

\section{Electrical resistivity tomography (ERT)}

Electrical resistivity tomography (ERT) was carried in November 2016 with 48 electrodes in the tunnel and 48 electrodes at the surface, with inter-distances of 4 and $5 \mathrm{~m}$, respectively (Fig. 2). Electrical resistivity measurements were acquired using an IRIS Syscal-Pro connected to a switch allowing current injections and measurements in between the tunnel and the surface. Such a configuration helps in constraining the medium properties at depth, notably close to the tunnel (Simyrdanis et al. 2015; Lesparre et al. 2016). Classical dipole-dipole and gradient protocols were used separately from the surface and from the tunnel. A third protocol was added by injecting current between the surface and the tunnel electrodes following a dipole-dipole AM-BN configuration with 1 injecting and 1 measuring electrode, both in the tunnel and at the surface (Bing and Greenhalgh 2001). Such a configuration was favored since it provided a higher sensitivity than regular AB-MN dipole-dipole (both injecting electrodes in the tunnel and both measuring electrodes at surface or the contrary) or pole-dipole configurations (one electrode at the infinite; Demirel and Candansayar 2017). In all, 12,682 data were acquired using the different protocols and 5,156 additional data were collected in a reciprocal mode to assess the data quality. Reciprocal measurements corresponded to a swap of the electrodes used for current injection and voltage measurements during the "normal" acquisition.

All the data sets (dipole-dipole, gradients and transmission) are gathered for the ERT inversion. Only data presenting a repeatability error lower than $1 \%$ and a normal to reciprocal difference lower than 5\% were selected. Additional filters are applied to keep only data with apparent resistivity in the range [0-40000] $\Omega . \mathrm{m}$, leading to a final set of 9,526 data that fulfilled the selection. The complete workflow for data selection, error analysis and weighting is provided in the electronic supplementary material (ESM). The medium is represented using a 3D finite element model built using Netgen and Gmsh softwares (Schöberl 1997; Geuzaine and Remacle 2009). The mesh of the forward model is unstructured and refined close to the electrodes for a better accuracy of the resistance estimation, while elements are coarser further away from the electrodes allowing a reduced computation time. The mesh includes the superficial topography as well as the abyss and the tunnel. The geometry of the investigated region is defined with a two-dimensional (2D) regular coarse mesh following a vertical plane between the surface and the tunnel. That second mesh is used to define the geometry of the resistivity values sought during the inversion. Thus, the sought resistivity values are defined in $2 \mathrm{D}$ and extruded in the threedimensional (3D) mesh for the forward model computations. This allows the drastic reduction of the number of sought values in the inversion, while the estimate of resistivity remains accurate since the forward problem includes the $3 \mathrm{D}$ geometry of the site. The measured resistances are inverted using the EIDORS software to obtain an image of the electrical resistivity distribution above the tunnel (Polydorides and Lionheart, 2002). Resistance values for a given distribution of electrical resistivity can then be estimated from the computation of the forward model with resistivity values allocated to each element. A cumulative sensitivity was used as a transparent filter to quantify uncertainty (Kemna 2000; Caterina et al. 2013).

\section{Seismic refraction tomography (SRT)}

Seismic data were acquired in October 2018 using four Geode seismic recorders (Geometrics) and $9614-\mathrm{Hz}$ vertical-component geophones. A total of 48 geophones were installed at the surface and 48 geophones in the tunnel, both with $4 \mathrm{~m}$ spacing. A total of 48 shots were performed about every $8 \mathrm{~m}$, both 
in the tunnel and at the surface, with a $5-\mathrm{kg}$ sledgehammer swung onto a metal plate. For each shot, seismic data were recorded simultaneously on all 96 geophones with a sampling rate of $0.125 \mathrm{~ms}$ and a recording time of $800 \mathrm{~ms}$, so as to obtain 4,608 traces. This acquisition setup allowed for the estimation of travel times in four different configurations: (1) surface to surface, (2) surface to tunnel, (3) tunnel to tunnel, and (4) tunnel to surface. Here again, the set-up of sensors and the possibility to shoot at depth allows increasing the image quality deeper, down to the tunnel (Maufroy et al. 2014).

A set of 3,367 travel times were picked manually on the recorded shot gathers, where signal-to-noise ratio is high enough to confidently identify first arrivals. These traveltime observations were then inversed for subsurface pressure-wave velocity structure $(\mathrm{Vp})$ using pyGIMLi refraction tomography inversion module (Rücker et al. 2017). In pyGIMLi, the inversion domain is parameterized in $2 \mathrm{D}$ as a sheared mesh of constant velocity triangles in which rays are traced using a shortest path algorithm (Dijkstra 1959; Moser 1991). Velocity updates are found in each of the 7,473 cells of the mesh using a generalized Gauss-Newton inversion framework. The program starts with an initial model consisting of a velocity field that increases linearly with depth, and then finds an appropriately smooth update to the model that reduces the difference between predicted and observed travel times. To quantify uncertainty and model the sensitivity, inversions were performed with 135 combinations of starting models and regularization parameters (Pasquet et al. 2016). Top velocity of the starting model ranged between 250 and $750 \mathrm{~m} / \mathrm{s}$; bottom velocity varied between 1,000 and $5,000 \mathrm{~m} / \mathrm{s}$. All the models presenting a satisfactory fit to the data are then eventually used to create an average final model. The final model has a travel-time mean absolute residuals of $5.3 \%$ for a root mean square error of $1.79 \mathrm{~ms}$.

\section{Time-lapse micro-gravimetry}

Nine couples of gravity stations were set along the tunnel, starting $50 \mathrm{~m}$ after the tunnel entrance with a spacing of $20 \mathrm{~m}$ (Fig. 2). For each station in the tunnel, a paired station was set up vertically at the surface on the nearest limestone solid outcrop. Precise positions and heights were obtained using a differential GPS (Trimble R8) outdoors, coupled to laser measurements (Trimble 5600) in the tunnel. Most of the 18 gravity stations ( 9 at the surface and 9 in the tunnel) were measured at least 3 times a year from December 2013 to September 2015 to sample the hydrological cycle: one measurement after the wet season (December/January), one at the end of the dry season (August/September) and one in between. The repetition of the measurements at the exact same positions and heights were ensured by setting bolts in the limestone outcrops or in the tunnel floor; and by blocking one foot of the CG5 tripod with a brass ring (Jacob et al. 2010). The same CG5 gravimeter (Scintrex Limited, 2006) was used for all measurements. This instrument has a standard field repeatability of $50 \mathrm{~nm} \mathrm{~s}^{-2}$ corresponding to a water slab variation of $120 \mathrm{~mm}$. The calibration factor of this CG5 instrument has always been kept up to date (Jacob et al. 2010; Champollion et al. 2018).

All the recommendations to minimize errors associated with gravimeter transport were applied (Lederer 2009), i.e. gently handling the gravimeter and settling it $2 \mathrm{~h}$ before starting the measurements after its transport by car to the site. CG5 measurements were programmed every $95 \mathrm{~s}$ (90-s reading, 5-s pause), following the recommendations of Merlet et al. (2008). The gravity value at one station is the mean of about several measurements of $90 \mathrm{~s}$, with variations depending on the repeatability (up to 15 measurements). All the surface measurements could not be performed each time because of a logging event and field mishaps. Indeed, an N/S strip of pines has been cleared during spring 2014 after the first gravity survey, right at the vertical of the tunnel (Fig. 1), leading to a few data gaps for stations pairs 6 and 7 .

The instrumental drift was determined and corrected by repeating the first station of the survey three times a day, following the measurement strategy of Champollion et al. (2018). The removal of all unwanted gravity temporal changes, including tides, atmospheric pressure or any other nonhydrological temporal variation over 1 day of survey is performed by subtracting the continuous and precise gravity monitoring of a superconducting gravimeter (SG), located $14 \mathrm{~km}$ away to the West (Fores et al. 2017). The correction of the topography and karstic voids effects were done using a precise digital elevation model of the site and a scan of the cave.

As stated in the introduction, making gravity differences between two stations vertically aligned provides the density of the slice between the two stations, assuming a onedimensional (1D) model (Jacob et al. 2009). After the corrections of earth tides and atmospheric pressure changes (and assuming that there are no surface deformation), variations of S2T gravity over time are expected to be related only to water mass changes above the tunnel. Therefore, there is a straightforward and linear relationship of between gravity S2T changes over time (also called double-difference) and equivalent water height changes in between both measuring points (Jacob et al. 2009; Champollion et al. 2018). The complete set of equations are available in the supplementary materials, as the novelty of this study lies in the possibility to investigate the lateral variability of S2T measurements thanks to the tunnel.

\section{Tracer experiment}

In order to study solute tracers' transport and their spatial variations in the unsaturated zone, a multitracer experiment 
was carried out on 16 March 2018, after a period of rain. Two tracers were injected simultaneously: $750 \mathrm{~g}$ of Fluorescein was injected on the sinkhole side in a rather clayey surface; and $250 \mathrm{~g}$ of Sulforhodamine B was injected on the abyss side (Fig. 2). These two tracers are easily detectable (around the $\mu \mathrm{g}$ $\mathrm{L}^{-1}$ ), conservative, little adsorbed by the soil but sensitive to light (Käss 1994). Both tracers were diluted in $2.5 \mathrm{~L}$ of water and $15 \mathrm{~L}$ of water were added to push the tracers in depth below the soil layer, down to the epikarst, and limit their adsorption by the soil. The excitation and emission wavelengths of the Fluorescein are 490 and $515 \mathrm{~nm}$, respectively, and 565 and $586 \mathrm{~nm}$ for Sulforhodamine B.

Groundwater that percolated in the tunnel roof was sampled manually by holding vials to gather the drops every 10 $20 \mathrm{~m}$ (Fig. 2). Samplings were made at specific dropping points or on a roof section, depending on the flow rate. The day of the injection, samplings were performed at least every hour to monitor the background noise level of tracer for concentration analyses. From March 19-22, a daily sampling was carried out. Then, the temporal sampling rate slowed down, with measurements on April 7, April 13 and May 5. All samples were kept in the dark until May 23rd, when they were analyzed using a PerkinElmer LS45 spectrofluorometer.

\section{Results}

\section{Electrical resistivity tomography}

The electrical resistivity image is displayed only for regions with a high sensitivity (Fig. 3). The electrical resistivity varies on a wide range spanning 6 orders of magnitude, the extreme values being located along the tunnel. At the surface, a region of high resistivity is visible below the sinkhole, where electrodes are located in a scree slope, just above the tunnel entrance. Then, outside of the sinkhole, the shallow subsurface is characterized by low resistivity values $(<500 \Omega$.m) down to a few meters depth, between 50 and $160 \mathrm{~m}$ from the tunnel entrance. This conductive region extends down to $20 \mathrm{~m}$ below the surface at the vertical around the $70 \mathrm{~m}$ landmark. On the north side, the resistivity is higher near the surface, locally above 7,500 $\Omega \mathrm{m}$. However the depth of that highly resistive medium cannot be accurately estimated due to the poor constraint in that region as illustrated by the low sensitivity values.

At depth, the south part of the tunnel shows very high resistivity values, globally above $10^{4} \Omega . \mathrm{m}$ and reaching locally $10^{6} \Omega$.m. Those high resistive patches are inserted in less resistive zones. Open fractures filled with conductive materials dividing rock in blocks might produce such patterns. However, the distance between the electrodes and the smooth regularization used in the inversion prevent the distinction of such thin and sharp structures. Moreover, the high resistivity values induce a low sensitivity in these regions since the electrical
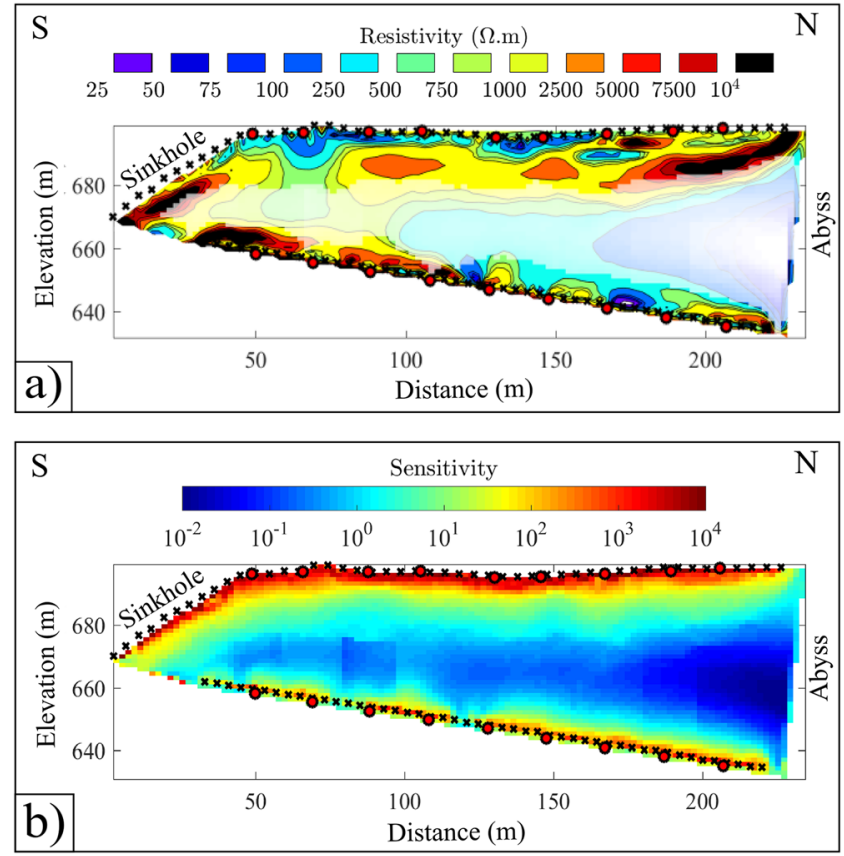

Fig. 3 a Electrical resistivity tomography and $\mathbf{b}$ sensitivity analysis. The black crosses indicate the electrodes and the red circles record the positions of the 9 gravity pairs of stations. The cross section is blanked where sensitivity is considered too low to be reliable

current circulation is very small. Along the north side of the tunnel, the resistivity values are lower than $1,000 \Omega . \mathrm{m}$. A restricted region with a very low resistivity below $50 \Omega$.m coincides with clay observed on the tunnel walls. Some higher resistivity patches might be related to the region less mechanically stable at the level of the masonry (160-195 m, Fig. 2). On the abyss side, $10 \mathrm{~m}$ above the tunnel, the resistivity presents values below $100 \Omega . \mathrm{m}$; nevertheless, the low sensitivity in that region prevents from assessing the dimension of that conductive zone. Thus, it remains difficult to delimit the boundary between the resistive zone below the surface from the conductive one above the tunnel on the north side of the tunnel.

\section{Seismic refraction tomography}

The pressure-wave velocity model obtained with SRT is represented on Fig. 4. The S2T configuration allows one to identify and pick travel times from a large number of sources and receivers pairs, thus considerably improving the resolution and coverage of the estimated Vp model. In this model, velocities vary between 500 and $5,000 \mathrm{~m} / \mathrm{s}$ and highlight three distinct zones within the investigated medium. A first zone, characterized by low velocities $(<1,500 \mathrm{~m} / \mathrm{s})$, covers the whole profile in the first $2-3 \mathrm{~m}$ below the surface. Underneath, intermediate velocities $(>1,500$ and $<3,000 \mathrm{~m} / \mathrm{s}$ ) extend down to $5 \mathrm{~m}$ at both ends of the profile, and down to about $25 \mathrm{~m}$ in its thickest part at about $110 \mathrm{~m}$ away from the sinkhole. Higher velocities $(>3,000 \mathrm{~m} / \mathrm{s})$ occur deeper and extend down to the 

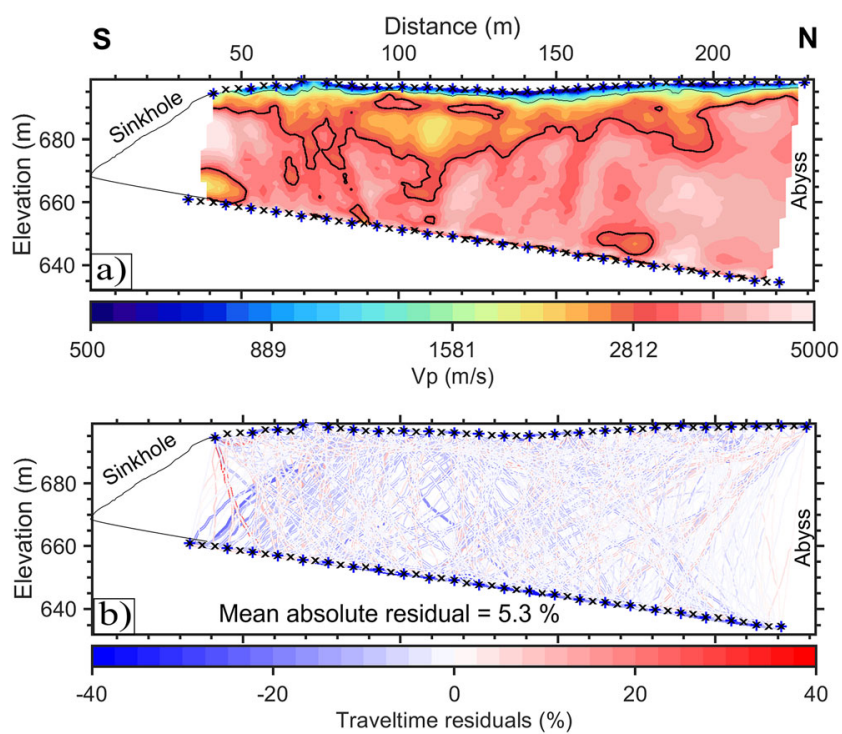

Fig. 4 a Seismic refraction tomography and $\mathbf{b}$ travel-time residuals. Black and blue crosses indicate geophones and sources, respectively. Contour lines at 1,500 and 30,00 m/s are represented with thick and thin black lines, respectively

tunnel. The wavelengths range from a few meters near the surface to a few tens of meters where the seismic velocities are the highest. Patches of intermediate velocities are also visible within this high velocity area, mostly at the beginning of the tunnel $(<50 \mathrm{~m})$ and above the masonry, as expected for the fragile rocks that needed reinforcements. Some of these patches are also present at $75 \mathrm{~m}$ from the entrance of the tunnel and seem to connect with the main intermediate velocity zone.

\section{Density profile}

The apparent density along the tunnel for each pair of station is computed from the mean of all gravity surveys (Fig. 5) with the error bars showing the minimum and maximum values. The apparent density appears to be constant at $2,530 \mathrm{~kg} \mathrm{~m}^{-3}$ from the sinkhole to $160 \mathrm{~m}$ (masonry in the tunnel) with a sharp and significant increase of $+25 \mathrm{~kg} \mathrm{~m}^{-3}$ to reach $2,555 \mathrm{~kg} \mathrm{~m}^{-3}$ after $180 \mathrm{~m}$. The porosity range is obtained directly from the apparent density profile assuming a homogeneous grain density of $2,700 \mathrm{~kg} \mathrm{~m}^{-3}$ (theoretical calcite value). The minimum and maximum porosity is evaluated by assuming the medium saturation to be 0 and $100 \%$ respectively. The porosity ranges from 5.5 to $10.0 \%$ with an average of $7.8 \pm 1.8 \%$, which is realistic and coherent with previous estimations on other karstic basins on the Larzac plateau (Jacob et al. 2009; Champollion et al. 2018).

\section{Water storage changes}

The S2T gravity difference $\left(\Delta_{z} g\right)$ is represented over time for each couple of gravity stations alongside meteorological data (Fig. 6). Gravity variations are coherent with meteorological data as S2T gravity increases after rainfall events and decreases after dry periods because of evapotranspiration but also because of water infiltration beneath the tunnel. The most important rain events take place between August 2014 and January 2015. The Alzon Météo-France station measures more than $800 \mathrm{~mm}$ of precipitation between these two surveys (Fig. 6). Globally, $\Delta_{z} g$ increases after rainy periods (August 2014 to January 2015; September 2015 to January 2016) and decreases after the dry season (December 2014 to August 2014; January 2015 to May 2015).

A strong spatial variability is also evidenced with much more important changes for stations 1 to $5(50-130 \mathrm{~m}$ from the entrance) than for stations 6 to 9 (150-210 $\mathrm{m}$ from the entrance). To highlight the spatial heterogeneity along the tunnel, Fig. 7 shows the gravity double differences $\left(\left(\Delta_{z}^{t} g\right)\right)$ along the tunnel, which correspond to the differences of $\Delta_{z} g$ between two successive surveys (Jacob et al. 2009; Champollion et al. 2018). Water storage changes are important on the southernmost point, near the sinkhole, and smoothly decreases until $150 \mathrm{~m}$ from the sinkhole entrance. From $150 \mathrm{~m}$ to the abyss, there are no significant water storage changes according to the gravity data. Such observations confirm the existence of strong lateral variations in water storage behavior between the surface and the tunnel.

\section{Tracer restitution}

The maximum restitution happens about 2 months (67 days) after the injections (last samplings on May 22, 2018) for both

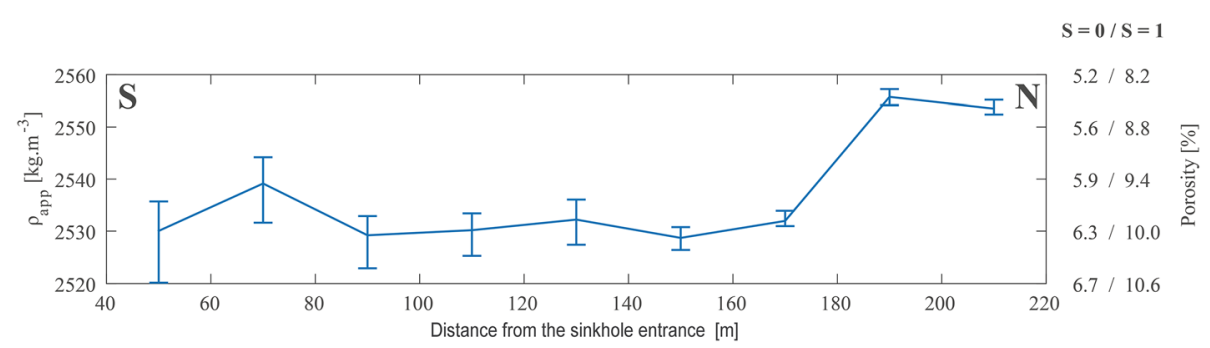

Fig. 5 Apparent density profile estimated from all surface-to-tunnel gravity differences ( 7 surveys over 2 years). The error bars show the maxima and minima when processing each survey separately. The right axis gives the equivalent porosity considering the medium either dry (saturation $S=$ 0 ) or completely saturated by water (saturation $S=1$ ) 
Fig. 6 a Surface-to-tunnel gravity monitoring for each vertical couple of stations (couple 1 is the southernmost and couple 9 the northernmost). The mean of each profile has been subtracted. $\mathbf{b}$ Potential evapotranspiration and precipitation from the Alzon Météo-France station ( $7 \mathrm{~km}$ to the north-east)
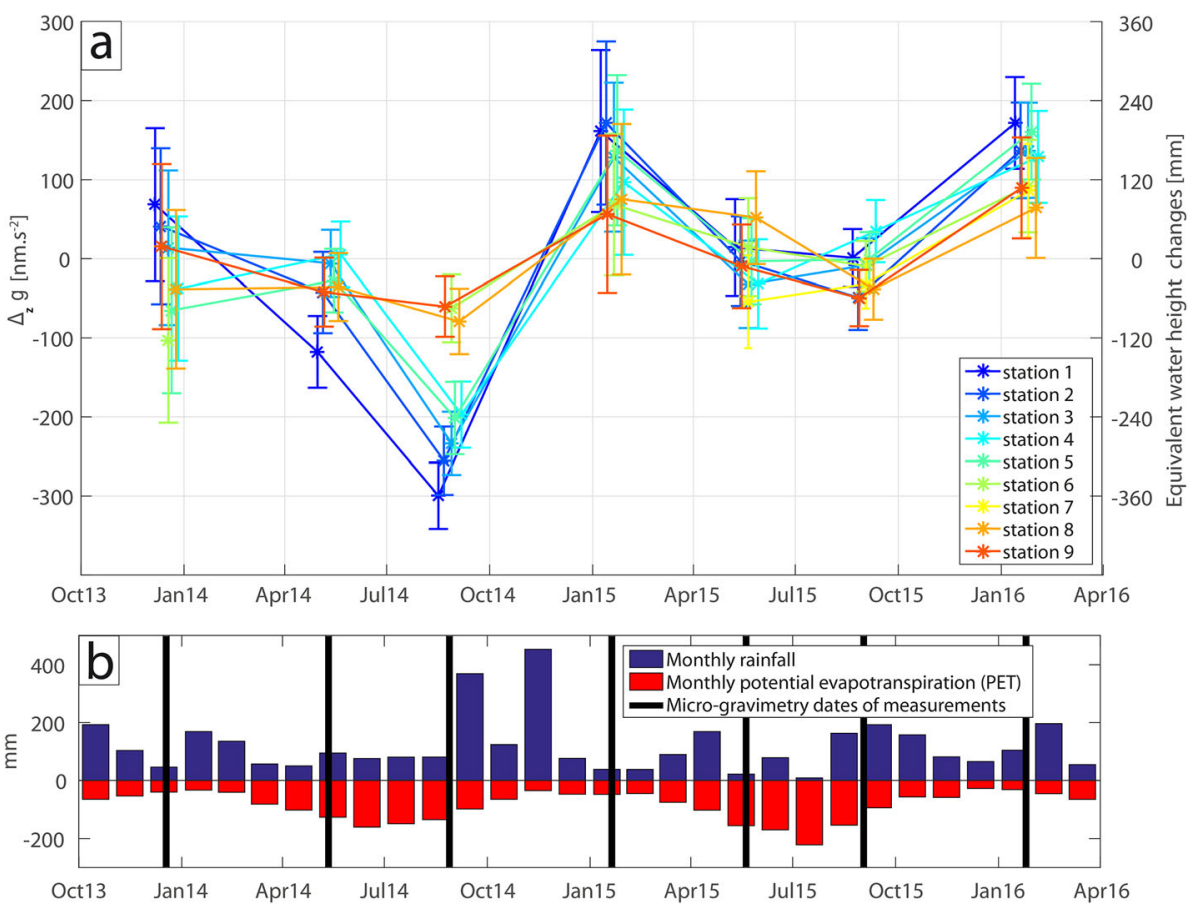

tracers, and for both tracers below their injection points (Fig. 8a): $74 \mathrm{~m}$ from the sinkhole for the Fluorescein and 162$170 \mathrm{~m}$ for B-Sulforhodamine. No significant response is observed in the drips sampled elsewhere in the tunnel. A fluorescein response were also detected a few days after the injection in the sampling points close to the vertical of the injection point of this tracer (30-74 $\mathrm{m}$ from the sinkhole entrance, Fig. $8 \mathrm{~b})$, while there is no B-Sulforhodamine response at all before May 22nd.

Thereby slow and vertical transfers of about $1 \mathrm{~m} /$ day can be estimated. Rapid and vertical transfers, close to the sinkhole only, are suggested by a small fluorescence peak on March 19, 3 days after the injection (Fig. 8b). One cannot completely exclude lateral N/S flows from the tracings, but this is coherent with the fractures observed in the tunnel which dip vertically to $50^{\circ} \mathrm{W}$ but never N/S. One also cannot exclude that a part of the water flow circumvents the tunnel or is directed westward by fractures.

\section{Discussion}

\section{Joint interpretation of the structural images}

The density profile, the SRT and ERT images show common features of the sounded karstic area and attest its
Fig. 7 Gravity double differences (changes in the surface-to-tunnel gravity difference between each consecutive survey) and equivalent water height changes for each couple of stations vertically aligned

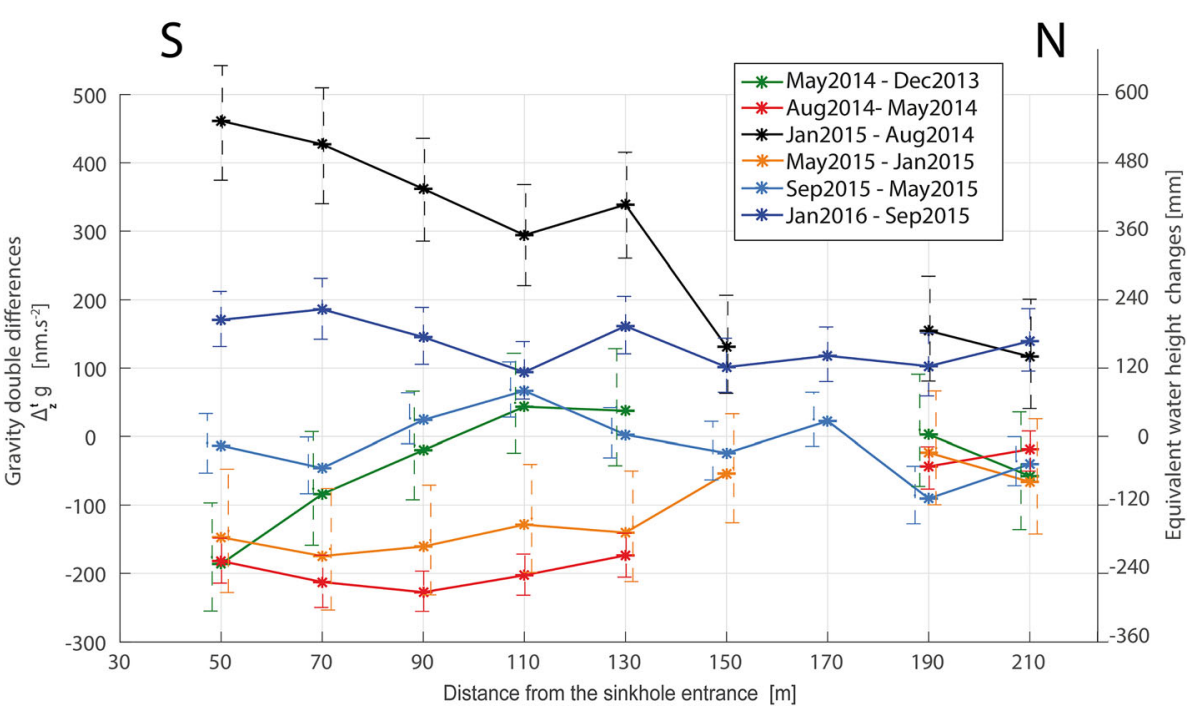


Fig. 8 a Normalized concentrations of Fluorescein and B-Sulforhodamine along the tunnel on 22 May 2018, which is the day of maximum restitution. $\mathbf{b}$ Fluorescein concentration over time for the sampling point vertically aligned with the injection (74 $\mathrm{m}$ from the sinkhole entrance) along with daily rainfalls
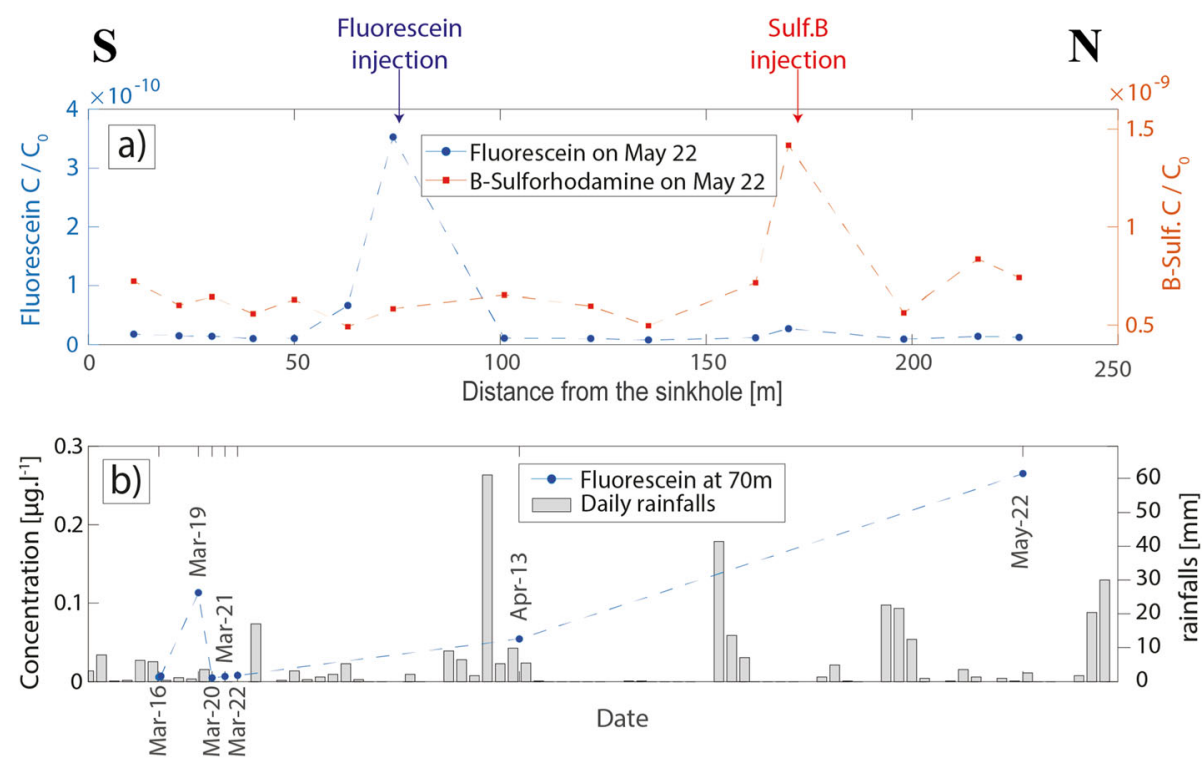

heterogeneous nature. Near the topographic surface, resistivity correlates with seismic velocity, especially close to the sinkhole and the abyss. From the sinkhole to $\sim 150 \mathrm{~m}$ northward, the low resistivity strip beneath the surface (250 and

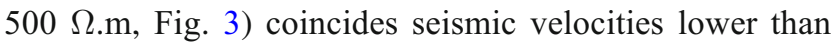
$1,000 \mathrm{~m} / \mathrm{s}$ in the very first meters and $2,000 \mathrm{~m} / \mathrm{s}$ in the first $10-20 \mathrm{~m}$ (Fig. 4). This shallow layer is about $5 \mathrm{~m}$ thick on the south edge and reaches $20 \mathrm{~m}$ deep $70 \mathrm{~m}$ away from the sinkhole. Close to the abyss, higher surface resistivity and surface velocities are present. Such a positive correlation between resistivity and seismic velocity can be related to different weathering stage of the carbonates. Massive limestone presents high $\mathrm{P}$ waves velocities and high resistivity. The alteration increases the porosity that reduces $\mathrm{P}$ wave velocity, and may be filled with more conductive material (water, organic matter, clay), lowering the resistivity. The thickness variation of this weathered layer is also coherent with the density increase northward according to the S2T gravimetry (Fig. 5). Since the tunnel is dipping progressively to the abyss, the gravity density sharp rise to the north might correspond to a larger proportion of healthy limestone. Following the classical vertical structure of the karst (Klimchouk 2004), this less dense, porous, weathered subsurface layer could be identified as the so-called epikarst.

Below the epikarst, the limestone is generally expected to be healthy with some fractures or much localized altered areas (the "infiltration zone"). Close to the tunnel roof, seismic velocities are high and homogeneous $(3,000-5,000 \mathrm{~m} / \mathrm{s})$ with weathering decreasing with depth (Fig. 4). However, ERT shows lateral variations, with a resistive south and a more conductive north (Fig. 3) and several small pockets of extreme resistivity values (very high or very low). Note that positive and negative targets influence differently both geophysical methods, which in addition have different resolution patterns. Highly conductive objects like small fractures filled by clay could have a large impact on the global resistivity even far from the electrodes (notion of short-circuit) but have little influence on the $\mathrm{P}$ wave velocity if the volume of clay is small compared to the sampled volume. In a more general way, anomalies larger than the methods resolution are correlated, but smaller anomalies can be uncorrelated. Note that the resolution depends on the wavelengths for the SRT, and electrodes spacing and protocol for the ERT. Then, high values of resistivity might reflect the presence of open fractures in the south, while spots of low resistivity might show the occurrence of fractures clogged by clay in the north. The observation of clay pockets on the tunnel walls around the abyss is another argument supporting this interpretation. Around 160-180 m close to the abyss a small anomaly of low velocity $(\sim 2,000 \mathrm{~m} / \mathrm{s})$ and very low resistivity (less than $100 \Omega . m$ ) is seen just above the tunnel. At this exact location, the tunnel is reinforced with masonry because of damages and instabilities which explains those geophysical observations.

The studied vertical profile exhibits two zones divided at about $130 \mathrm{~m}$ with different features that might induce the observed temporal dynamics from the tracer test, the drip flows and the gravity. All the complementary information gathered on that particular site provides clues to sketch the distinct hydrological processes susceptible to occur so closely in karstic environments.

\section{Hydrological processes on the southern side}

S2T gravity measurements (Figs. 6 and 7) show important water mass changes on the southern side. The water storage increases during the "wet" seasons (up to $450 \mathrm{~nm} \mathrm{~s}^{-2}$, i.e. $500 \mathrm{~mm}$ of water). A porous reservoir, that may be an intermittent perched aquifer, must exist to support this groundwater transient storage. Such a reservoir might correspond to the weathered shallow region revealed by the geophysical images. 
This subsurface layer, identified as the epikarst is thicker in the south (between 50-90 m, Fig. 3), where gravity changes are the highest (Fig. 7).

On this south part, the drip flows observed in the tunnel depend on the climatic context, drying up in summer and immediately restarting after significant rainfalls. The tracing tests have demonstrated the presence of vertical flows with two residence times: a very fast one (a few days) and a slow transfer ( 2 months). Then one can infer that the south epikarst reservoir acts as a buffer distributing the water by slow water percolation through the underlying less permeable infiltration zone (5-20 $\mathrm{m}$ deep to the tunnel and below). The presence of open fractures is deduced from the ERT and SRT images, which is coherent with the drip reactivity to rainfalls and the tracing test. In terms of processes, seasonal storage is located in a shallow weathered porous limestone with a transfer through vertical fractures. Fast transfer is enhanced when the reservoir reaches water saturation

\section{Hydrological processes on the northern side}

Perennial flows are observed on the northern side, with a variable rate depending on the season. The tracing shows only vertical and slow transfer (more than one month). Seasonal water storage from gravity observations is almost insignificant ( $\pm 100 \mathrm{~mm}$ of water) over 3 years. This is in agreement with the geophysical images showing almost no weathered epikarst and an infiltration zone composed of healthy limestone with fractures partially clogged with clay. The saturation in the infiltration zone must remain constant and near the saturation to allow perennial flow and the absence of transient storage. Evidence of high saturation in the infiltration zone has already been described in the Larzac plateau from magnetic resonance soundings experiment (Mazzilli et al. 2016).

In terms of processes, both storage and transfers differ from the south side. In the north a vertical transfer is assumed, thanks to a piston mechanism (Aquilina et al. 2006) that explains the absence of gravity changes (all the incoming water pushing an equivalent quantity), the reactivity of drip flows to rainfall and the slow tracer restitution. Clays in fractures reduce the available space for water and could explain the triggering of this piston effect at low water contents. Clays may also prevent a good drainage, so the reactivity to rain is lower than on the sinkhole side and flows are perennial. A summarizing scheme of the identified hydrological processes and structures conciliates all observations gathered (Fig. 9).

\section{Conclusions}

The site configuration with a surface-to-tunnel geometry provides a unique way to observe and understand karst heterogeneity at the scale of few hundreds of meters. Geophysical images reveals that the epikarst, an equivalent porous subsurface layer acting like a reservoir, has a variable thickness. Time-lapse S2T gravity suggests that this reservoir can store up to $80 \%$ of the rainfall, distributing the water through open fractures in the underlying healthy limestone. The surface reservoir thins up and almost disappears where the water storage is divided by a factor of 5. In depth, limestone is massive as shown by the high seismic velocities, while the varying resistivity is interpreted by distinct clay content. While open fractures seem to dominate below the epikarst reservoir, a substantial clay content may clog the vertical fractures where the
Fig. 9 Interpretation of the site based on all the geophysical and hydrological experiments. The karstic compartments (epikarst/ infiltration zone) and the clay content are deduced from the relations between the ERT and SRT images. The reservoir role and flows path are deduced from the time-lapse gravity and tracing experiments

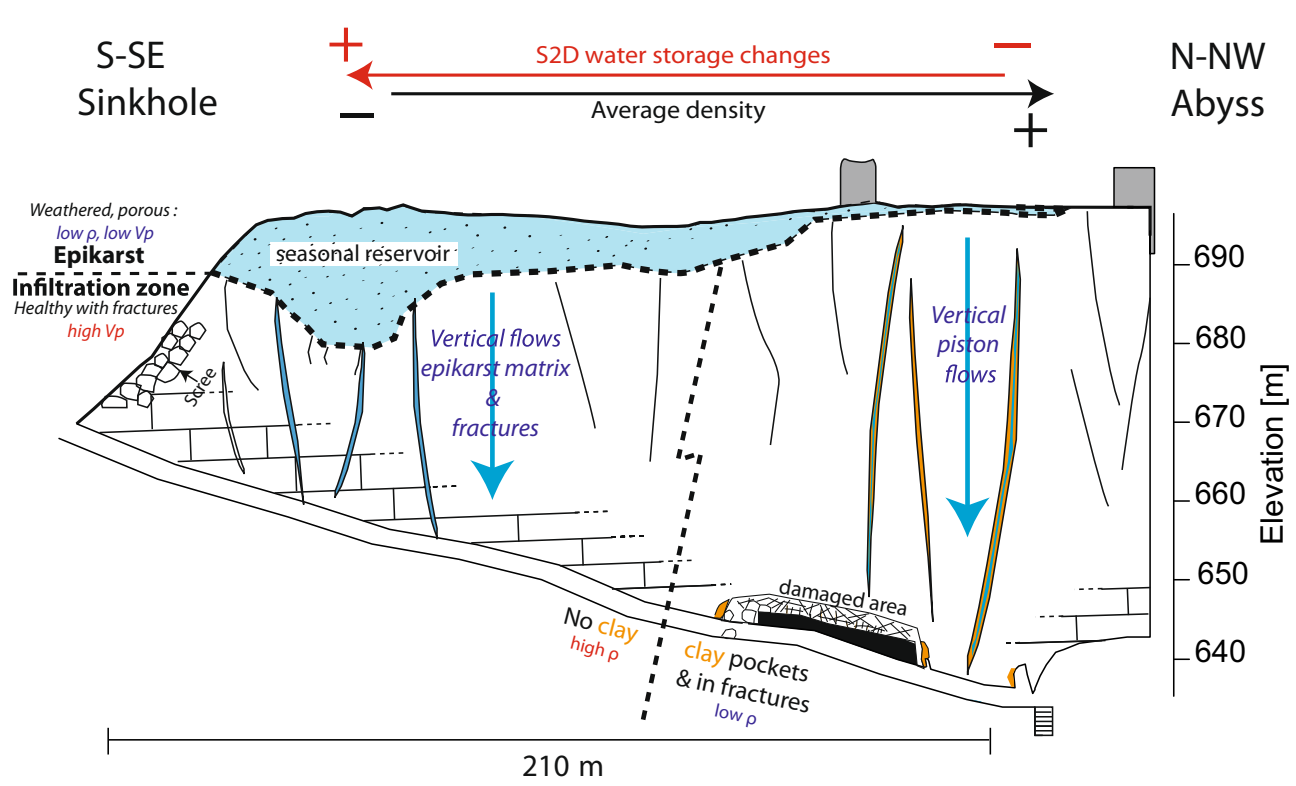


reservoir thins. This is also consistent with tracer tests showing only vertical flows, with a fast and slow transport underneath the thick epikarst, and only a slow transport underneath the massive limestone where clay is imaged.

In terms of methodology, the three geophysical methods provide complementary information for a joint interpretation of the underground structures. The different properties imaged (electrical resistivity, $\mathrm{p}$ wave velocities and density) are often consistent. This is the case for the weathered epikarst with a high porosity filled with water, and consequently low density, $p$ wave velocity and resistivity. However, geophysical properties might reveal apparent contradictions where the resolution power or the sensitivity of the methods strongly differ. That is why a multimethod approach is valuable but needs to account for the specific resolution loss and uncertainty of each method. This study also demonstrates the importance of combining geophysical imaging with time-lapse measurements and tracer tests relating the observed structures, to solute transport and water storage processes to provide tangible data on actual conceptual models that would remain hypothesis otherwise. This type of experiment, which is seldomly available, should be encouraged and repeated where possible in order to validate conceptual models and to provide fundamental understanding of systems inherently difficult if not impossible to observe directly.

Supplementary Information The online version contains supplementary material available at https://doi.org/10.1007/s10040-021-02365-5.

Acknowledgements The Scintrex CG5 relative gravimeter was loaned by the Gravity Mobile facility (GMOB) of RESIF-INSU. We thank N. Denchik, S. Baudin, E. Doerflinger, J. Chéry, O. Khairoun, S. Furst, A. Maréchal, G. Mainsant, A-K. Cooke and A. Fort for their help during the field experiments. We are grateful to Eric Cotteux (ITAP IRSTEA) for the Spectrometer and tracings equipment, and to Thomas Kremer for Magnetic Resonance Soundings attempts. The seismic equipment was provided by the CRITEX ANR-11-EQPX-0011 project and the METIS laboratory at Sorbonne Université. We would also like to acknowledge the farmer who let us access the cave. All the data used in this study (geophysics, tracers and meteorological data) are available on the OSU OREME observatory website (http://data.oreme.org/gek/home).

Funding Gravity surveys were part of the OSU OREME observatory funded by the Institut de Recherche pour le Développement (IRD) and the Institut National des Sciences de l'Univers (INSU) and of the National observation system (SNO) H+. N. Lesparre benefited from a BEcome a WAlloon REsearcher fellowship fund co-financed by the Department of Research Programs of the Federation Wallonia - Brussels and the COFUND program of the European Union that both founded the project SUITE4D.

\section{References}

Aquilina L, Ladouche B, Dörfliger N (2006) Water storage and transfer in the epikarst of karstic systems during high flow periods. J Hydrol 327(3-4):472-485. https://doi.org/10.1016/j.jhydrol.2005.11.054
Al-Fares W, Bakalowicz M, Guérin R, Duckam M (2002) Analysis of the karst aquifer by means of a ground penetrating radar (GPR): example of the Lamalou area (Hérault, France). J Appl Geophys 51(2-4): 97-106. https://doi.org/10.1016/S0926-9851(02)00215-X

Bicalho CC, Batiot-Guilhe C, Taupin JD, Patris N, Van Exter S, Jourde H (2019) A conceptual model for groundwater circulation using isotopes and geochemical tracers coupled with hydrodynamics: a case study of the Lez karst system, France. Chem Geol 528:118442. https://doi.org/10.1016/j.chemgeo.2017.08.014

Bing Z, Greenhalgh SA (2001) Cross-hole resistivity tomography using different electrode configurations. Geophys Prospect 48(5):887912. https://doi.org/10.1046/j.1365-2478.2000.00220.x

Bruxelles L (2001) Dépôts et altérites des plateaux du Larzac central: Causses de l'Hospitalet et de Campestre (Aveyron, Gard, Hérault) - evolution morphogénétique, conséquences géologiques et implications pour l'aménagement [Deposits and alterites of plateau of Larzac central: causses from l'Hospitalet and de Campestre (Aveyron, Gard, Hérault) - morphogenetic evolution, geological consequences and implications for development]. PhD Thesis, Aix-Marseille 1, France

Caterina D, Beaujean J, Robert T, Nguyen F (2013) A comparison study of different image appraisal tools for electrical resistivity tomography. Near Surf Geophys 11(6):639-658. https://doi.org/10.3997/ 1873-0604.2013022

Carriere SD, Chalikakis K, Sénéchal G, Danquigny C, Emblanch C (2013) Combining electrical resistivity tomography and ground penetrating radar to study geological structuring of karst unsaturated zone. J Appl Geophys 94:31-41. https://doi.org/10.1016/j.jappgeo. 2013.03.014

Chalikakis K, Plagnes V, Guerin R, Valois R, Bosch FP (2011) Contribution of geophysical methods to karst-system exploration: an overview. Hydrogeol J 19(6):1169. https://doi.org/10.1007/ s10040-011-0746-x

Champollion C, Deville S, Chery J, Doerflinger E, Le Moigne N, et al (2018) Estimating epikarst water storage by time-lapse surface-todepth gravity measurements. https://doi.org/10.5194/hess-22-38252018

Creutzfeldt B, Güntner A, Thoss H, Merz B, Wziontek H (2010) Measuring the effect of local water storage changes on in situ gravity observations: case study of the geodetic observatory Wettzell, Germany. Water Resour Res 46(8). https://doi.org/10.1029/ 2009WR008359

Dausse A, Jourde H, Léonardi V (2015) Multi-scale assessment of hydrodynamic properties in a karst aquifer (Lez, France). In: Hydrogeological and environmental investigations in karst systems. Springer, Heidelberg, pp 331-338. https://doi.org/10.1007/978-3642-17435-3_37

Demirel C, Candansayar ME (2017) Two-dimensional joint inversions of cross-hole resistivity data and resolution analysis of combined arrays. Geophys Prospect 65(3):876-890. https://doi.org/10.1111/ 1365-2478.12432

Dentz M, Le Borgne T, Englert A, Bijeljic B (2011) Mixing, spreading and reaction in heterogeneous media: a brief review. J Contam Hydrol 120:1-17. https://doi.org/10.1016/j.jconhyd.2010.05.002

Dijkstra EW (1959) A note on two problems in connexion with graphs. Numer Math 1(1):269-271

Dubois C, Quinif Y, Baele JM, Barriquand L, Bini A, Bruxelles L et al (2014) The process of ghost-rock karstification and its role in the formation of cave systems. Earth Sci Rev 131:116-148. https://doi. org/10.1016/j.earscirev.2014.01.006

Dussauge-Peisser C, Wathelet M, Jongmans D, Hantz D, Couturier B, Sintes M (2003) Investigation of a fractured limestone cliff (Chartreuse Massif, France) using seismic tomography and ground-penetrating radar. Near Surf Geophys 1(4):161-170. https://doi.org/10.3997/1873-0604.2003007 
Ford D, Williams PD (2013) Karst hydrogeology and geomorphology. Wiley, Chichester, UK

Fores B, Champollion C, Moigne NL, Bayer R, Chery J (2017) Assessing the precision of the iGrav superconducting gravimeter for hydrological models and karstic hydrological process identification. Geophys J Int 208(1):ggw396. https://doi.org/10.1093/gji/ggw396

Gallardo LA, Meju MA (2003) Characterization of heterogeneous nearsurface materials by joint $2 \mathrm{D}$ inversion of dc resistivity and seismic data. Geophys Res Lett 30(13). https://doi.org/10.1029/ 2003GL017370

Geuzaine C, Remacle JF (2009) A three-dimensional finite element mesh generator with built-in pre-and post-processing facilities. Int $\mathrm{J}$ Numer Methods Eng 79(11):1309-1331. https://doi.org/10.1002/ nme. 2579

Gehman CL, Harry DL, Sanford WE, Stednick JD, Beckman NA (2009) Estimating specific yield and storage change in an unconfined aquifer using temporal gravity surveys. Water Resour Res 45(4). https:// doi.org/10.1029/2007WR006096

Gèze B (1985) Notice explicative de la feuille de Nant à 1/50 000 [Explanatory note of the 1:50 000 Nant geological map]. BRGM, Orléans, France

Gritto R, Korneev VA, Daley TM, Feighner MA, Majer EL, Peterson JE (2004) Surface-to-tunnel seismic tomography studies at Yucca Mountain, Nevada. J Geophys Res: Solid Earth 109(B3). https:// doi.org/10.1029/2002JB002036

Hartmann A, Goldscheider N, Wagener T, Lange J, Weiler M (2014) Karst water resources in a changing world: review of hydrological modeling approaches. Rev Geophys 52(3):218-242. https://doi.org/ 10.1002/2013RG000443

Hinderer J, Hector B, Mémin A, Calvo M (2016) Hybrid gravimetry as a tool to monitor surface and underground mass changes. In: International Symposium on Earth and Environmental Sciences for Future Generations. Springer, Cham, Switzerland, pp 123-130

Jacob T, Chery J, Bayer R, Le Moigne N, Boy JP, Vernant P, Boudin F (2009) Time-lapse surface to depth gravity measurements on a karst system reveal the dominant role of the epikarst as a water storage entity. Geophys J Int 177(2):347-360. https://doi.org/10.1111/j. 1365-246X.2009.04118.x

Jacob T, Bayer R, Chery J, Le Moigne N (2010) Time-lapse microgravity surveys reveal water storage heterogeneity of a karst aquifer. $\mathrm{J}$ Geophys Res: Solid Earth 115(B6). https://doi.org/10.1029/ 2009JB006616

Jeannin M, Garambois S, Grégoire C, Jongmans D (2006) Multiconfiguration GPR measurements for geometric fracture characterization in limestone cliffs (Alps). Geophysics 71(3):B85-B92

Käss WA (1994) Hydrological tracing practice on underground contaminations. Environ Geol 23(1):23-29

Kemna A (2000) Tomographic inversion of complex resistivity: theory and application. Der Andere Verlag, Tönning, Germany

Klimchouk A (2004) Towards defining, delimiting and classifying epikarst: its origin, processes and variants of geomorphic evolution. Speleogen Evolution Karst Aquifers 2(1):1-13

Lederer M (2009) Accuracy of the relative gravity measurement. Acta Geodyn Geomater 6(3):155

Lesparre N, Boyle A, Grychtol B, Cabrera J, Marteau J, Adler A (2016) Electrical resistivity imaging in transmission between surface and underground tunnel for fault characterization. J Appl Geophys 128: 163-178. https://doi.org/10.1016/j.jappgeo.2016.03.004

Mangin A (1975) Contribution à l'étude hydrodynamique des aquifères karstiques [Insights into hydrodynamic behaviour of karst aquifers]. $\mathrm{PhD}$ Thesis, Université de Dijon, France

Maufroy E, Gaffet S, Operto S, Guglielmi Y, Boyer D (2014) Travel time inversion from ground level to gallery: protocol for the characterization of P-wave seismic signature in a fractured-porous Urgonian platform at hectometric scale. Near Surf Geophys 12(6):697-708. https://doi.org/10.3997/1873-0604.2014025
Mazzilli N, Boucher M, Chalikakis K, Legchenko A, Jourde H, Champollion C (2016) Contribution of magnetic resonance soundings for characterizing water storage in the unsaturated zone of karst aquifers. Geophysics 81(4):WB49-WB61. https://doi.org/10.1190/ GEO2015-0411.1

Mazzilli N, Bertin D, Jourde H, Lecoq N, Labat D, Danquigny C, Arfib B, Dal Soglio L (2019) KarstMod: a modelling platform for rainfalldischarge analysis and modelling dedicated to karst systems. Environ Model Softw 122:103927. https://doi.org/10.1016/j. envsoft.2017.03.015

Merlet S, Kopaev A, Diament M, Geneves G, Landragin A, Dos Santos FP (2008) Micro-gravity investigations for the LNE watt balance project. Metrologia 45(3):265

Moser TJ (1991) Shortest path calculation of seismic rays. Geophysics 56(1):59-67. https://doi.org/10.1190/1.1442958

Noushabadi MJ, Jourde H, Massonnat G (2011) Influence of the observation scale on permeability estimation at local and regional scales through well tests in a fractured and karstic aquifer (Lez aquifer, southern France). J Hydrol 403(3-4):321-336. https://doi.org/10. 1016/j.jhydrol.2011.04.013

Novitsky CG, Holbrook WS, Carr BJ, Pasquet S, Okaya D, Flinchum BA (2018) Mapping inherited fractures in the critical zone using seismic anisotropy from circular surveys. Geophys Res Lett 45(7):31263135. https://doi.org/10.1002/2017GL075976

Pasquet S, Holbrook WS, Carr BJ, Sims KWW (2016) Geophysical imaging of shallow degassing in a Yellowstone hydrothermal system. Geophys Res Lett 43(23):12-027. https://doi.org/10.1002/ 2016GL071306

Pfeffer J, Champollion C, Favreau G, Cappelaere B, Hinderer J, et al (2013) Evaluating surface and subsurface water storage variations at small time and space scales from relative gravity measurements in semiarid Niger. Water Resour Res 49(6):3276-3291. https://doi.org/ 10.1002/wrcr.20235

Piccolroaz S, Majone B, Palmieri F, Cassiani G, Bellin A (2015) On the use of spatially distributed, time-lapse microgravity surveys to inform hydrological modeling. Water Resour Res 51(9):7270-7288. https://doi.org/10.1002/2015WR016994

Polydorides N, Lionheart WR (2002) A MATLAb toolkit for threedimensional electrical impedance tomography: a contribution to the electrical impedance and diffuse optical reconstruction software project. Meas Sci Technol 13(12):1871

Robert T, Dassargues A, Brouyère S, Kaufmann O, Hallet V, Nguyen F (2011) Assessing the contribution of electrical resistivity tomography (ERT) and self-potential (SP) methods for a water well drilling program in fractured/karstified limestones. J Appl Geophys 75(1): 42-53. https://doi.org/10.1016/j.jappgeo.2011.06.008

Robert T, Caterina D, Deceuster J, Kaufmann O, Nguyen F (2012) A salt tracer test monitored with surface ERT to detect preferential flow and transport paths in fractured/karstified limestones. Geophysics 77(2):B55-B67. https://doi.org/10.1190/geo2011-0313.1

Rücker C, Günther T, Wagner FM (2017) pyGIMLi: an open-source library for modelling and inversion in geophysics. Comput Geosci 109:106-123. https://doi.org/10.1016/j.cageo.2017.07.011

Schöberl J (1997) NETGEN an advancing front 2D/3D-mesh generator based on abstract rules. Comput Vis Sci 1(1):41-52

Scintrex Limited (2006) CG-5 Scintrex autograv system operation manual. Scintrex, Concord, ON

Simyrdanis K, Tsourlos P, Soupios P, Tsokas G, Kim JH, Papadopoulos N (2015) Surface-to-tunnel electrical resistance tomography measurements. Near Surf Geophys 13(4):343-354. https://doi.org/10. 3997/1873-0604.2015019

Tsourlos P, Ogilvy R, Papazachos C, Meldrum P (2011) Measurement and inversion schemes for single borehole-to-surface electrical resistivity tomography surveys. J Geophys Eng 8(4):487-497. https:// doi.org/10.1088/1742-2132/8/4/001 
Valois R, Camerlynck C, Dhemaied A, Guerin R, Hovhannissian G, Plagnes V, Rejiba F, Robain H (2011) Assessment of doline geometry using geophysics on the Quercy plateau karst (South France). Earth Surf Process Landf 36(9):1183-1192. https://doi.org/10.1002/ esp. 2144

Valois R, Galibert PY, Guerin R, Plagnes V (2016) Application of combined time-lapse seismic refraction and electrical resistivity tomography to the analysis of infiltration and dissolution processes in the epikarst of the Causse du Larzac (France). Near Surf Geophys 14(1): 13-22. https://doi.org/10.3997/1873-0604.2015052

Vouillamoz JM, Legchenko A, Albouy Y, Bakalowicz M, Baltassat JM, Al-Fares W (2003) Localization of saturated karst aquifer with magnetic resonance sounding and resistivity imagery. Groundwater 41(5):578-586. https://doi.org/10.1111/j.1745-6584. 2003.tb02396.x

Watlet A, Kaufmann O, Triantafyllou A, Poulain A, Chambers JE, Meldrum PI, Camp MV (2018) Imaging groundwater infiltration dynamics in the karst vadose zone with long-term ERT monitoring. Hydrology and Earth System Sciences 22(2):1563-1592

Publisher's note Springer Nature remains neutral with regard to jurisdictional claims in published maps and institutional affiliations. 